\title{
Genetic variations of TLR5 gene interacted with Helicobacter pylori infection among carcinogenesis of gastric cancer
}

\author{
Tianwen Xu ${ }^{1}$, Deqiang Fu ${ }^{1}$, Yi Ren ${ }^{2}$, Yijun Dai ${ }^{1}$, Jianguang Lin ${ }^{1}$, Liming Tang ${ }^{3}$, Jian $\mathrm{Ji}^{4}$ \\ ${ }^{1}$ Department of Oncology, The Second Affiliated Hospital of Fujian Medical University, China \\ ${ }^{2}$ Department of Thyroid and Breast, Huai'an First People's Hospital, Nanjing Medical University, China \\ ${ }^{3}$ No. 2 People's Hospital of Henan Province, China \\ ${ }^{4}$ Department of Thoracic Surgery, Huai'an First People's Hospital, Nanjing Medical University, China
}

Correspondence to: Jian Ji, email: jijian_huaian@sina.com

Keywords: gastric cancer, variation, genetic, TLR5, helicobacter pylori

Received: December 14, 2016

Accepted: January 11, 2017

Published: March 09, 2017

Copyright: Xu et al. This is an open-access article distributed under the terms of the Creative Commons Attribution License (CC-BY), which permits unrestricted use, distribution, and reproduction in any medium, provided the original author and source are credited.

\section{ABSTRACT}

Gastric cancer (GC) ranks the second prevalent cancer type and the second cancer-related death in China. However, the precise mechanisms of GC development remain poorly understood. Chronic infection with Helicobacter pylori is the strongest identified risk factor for GC. Toll-like receptor (TLR) genes, which play critical roles in Helicobacter pylori induced chronic inflammation, may also be implicated in GC susceptibility. TLR5 signaling deficiency could deregulate a cascade of inflammatory events. In current study, we systematically evaluated genetic variations of TLR5, and their interaction with Helicobacter pylori infection among carcinogenesis of gastric cancer, using a large case-controls study among Chinese population. Minor alleles of three SNPS, including rs5744174 $(P=0.001), \operatorname{rs1640827}(P=0.005)$, and rs17163737 $(P=0.004)$, were significantly associated with increased GC risk (OR ranged from 1.20-1.24). Significant interactions with Helicobacter pylori infection were also identified for rs1640827 ( $P$ for interaction $=0.009$ ) and rs17163737 ( $P$ for interaction $=\mathbf{0 . 0 0 6}$ ). These findings suggest that genetic variants in TLR5 may modify the role of Helicobacter pylori infection in the process of causing GC.

\section{INTRODUCTION}

Gastric cancer (GC), the second frequent cause of cancer-related deaths worldwide, remains one of the major problem of public health [1]. Its incidence rates are highest in Eastern Asia, particularly in China, Korea, Mongolia, and Japan [2]. According to the program of surveillance and health services research of American Cancer Society, 26,370 estimated new GC cases and 10,730 deaths were diagnosed in USA in 2016, during which approximately twice as high in men as in women and vary widely across States [3]. In China, the situation that $\mathrm{GC}$ ranks the second prevalent cancer type and the second cancer-related death should drew more attention [4]. According to the National Office for Cancer Prevention and Control of China (NOCPCC), 679.1 thousands new GC cases and 498.0 deaths were found in China in 2015 [4]. Chronic infection with Helicobacter pylori, accounting about $90 \%$ of new cases of noncardia gastric cancer worldwide, is the strongest identified risk factor for $\mathrm{GC}$ development [2, 4-11]. Despite accumulating evidence indicating the involvement of multiple gene-environment interactions with Helicobacter pylori infection, the precise mechanisms of GC development remain poorly understood.

Genetic polymorphisms in inflammatory responserelated genes has been identified to contribute to susceptibility of GC and its precursors [12, 13]. Tolllike receptor (TLR) genes, which play critical roles in Helicobacter pylori induced chronic inflammation, may also be implicated in GC susceptibility [14-16]. TLR5 signaling deficiency could change interactions with commensal microbiota and deregulate a cascade of inflammatory events that can suppress or accelerate extra-intestinal cancers $[17,18]$. Functional TLR5 genetic variants could also affect human colorectal cancer survival [19]. Here, we systematically evaluated the function of genetic variations of TLR5, and their interaction with 
Helicobacter pylori infection among carcinogenesis of gastric cancer in a Chinese population.

\section{RESULTS}

\section{Basic characteristics of study subjects}

Totally included in this study were 1,300 GC cases and 1,300 healthy controls. Detailed information on the basic characteristics of the study population is presented in Table 1. There were no significant differences in age, gender, education level, body mass index, and drinking status between the GC patients and the controls. However, significant difference was detected for the distributions of residence $(P=0.028)$, smoking status $(P<0.001)$, and Helicobacter pylori infection $(P<0.001)$ between the two groups, which indicates rural residence, smoking, and Helicobacter pylori infection are risk factors for the susceptibility of GC.

\section{Association between TLR5 gene polymorphisms and risk of GC}

In current study, 7 tagSNPs of TLR5 gene, including rs5744174, rs5744140, rs5744113, rs1640827, rs2241096, rs17163737, and rs2241097, were evaluated for their association with susceptibility of GC (Table 2). All the seven SNPs did not depart from the HardyWeinberg equilibrium in the healthy controls $(p>0.05)$. As shown in Table 3, we found minor alleles of rs5744174 $(P=0.001), \operatorname{rs} 1640827(P=0.005)$, and rs17163737 $(P=0.004)$ were significantly associated with increased GC risk (OR ranged from 1.20-1.24). Even adjusted for Bonferroni correction, the results were still significant $(P=0.001 * 7=0.007 ; P=0.005 * 7=0.035$; $P=0.004 * 7=0.028)$. For rs 5744174 , carriers of genotype $\mathrm{TC}(\mathrm{OR}=1.18 ; 95 \%=1.00-1.39 ; P=0.047)$ and $\mathrm{CC}(\mathrm{OR}$ $=1.68 ; 95 \%=1.18-2.41 ; P=0.004)$ have a higher GC risk, compared with carriers of genotype TT. For rs1640827, carriers of genotype TC $(\mathrm{OR}=1.19 ; 95 \%=1.00-1.41$; $P=0.048)$ and $\mathrm{CC}(\mathrm{OR}=1.69 ; 95 \%=1.08-2.62$; $P=0.021$ ) have a higher GC risk, compared with carriers of genotype TT. For rs17163737, carriers of genotype GT $(\mathrm{OR}=1.19 ; 95 \%=1.01-1.40 ; P=0.034)$ and TT $(\mathrm{OR}=1.41 ; 95 \%=1.05-1.90 ; P=0.023)$ have a higher GC risk, compared with carriers of genotype GG. We didn't detected any significant associations for including rs5744140, rs5744113, rs2241096, and rs2241097. Sensitivity analyses were also conducted by including other non-significant variables in Table 1, however, the results were not changed (data not shown).

\section{Interaction analyses between TLR5 gene polymorphisms and Helicobacter pylori infection}

We also evaluated the joint effects of TLR5 gene polymorphisms and Helicobacter pylori infection on GC
(Table 4). Significant interactions with Helicobacter pylori infection were identified for rs1640827 (P for interaction $=0.009)$ and rs17163737 (P for interaction $=0.006)$. For SNP rs1640827, we found 2.13-fold elevated GC risk for subjects with genotype $\mathrm{TC}+\mathrm{CC}$ and with Helicobacter pylori infection $(\mathrm{OR}=2.13,95 \% \mathrm{CI}: 1.79-2.53)$. While for SNP rs17163737, we found 2.17-fold elevated GC risk for subjects with genotype GT+TT and with Helicobacter pylori infection $(\mathrm{OR}=2.17,95 \% \mathrm{CI}: 1.81-2.61)$. However, no statistically significant interaction between rs5744174 and Helicobacter pylori infection was found.

\section{DISCUSSION}

The current study systematically explored the function of genetic variations of TLR5, and their interaction with Helicobacter pylori infection among carcinogenesis of gastric cancer in a Chinese population, using a large scale, case-control study. TLR5, which could recognize bacterial flagellin from invading mobile bacteria, has an close relationship with Helicobacter pylori infection [20-22]. We found rs5744174, rs1640827 and rs17163737 were significantly associated with increased GC risk. Also, significant interactions with Helicobacter pylori infection were also identified for rs1640827 and rs17163737. To our best knowledge, this should be the largest, and most comprehensive study to systematically explore genetic variations of TLR5, and their interaction with Helicobacter pylori infection among carcinogenesis of gastric cancer.

GC remains a major public health problem and disease burden in China. Infection of Helicobacter pylori, a Gram-negative, microaerophilic, flagellated bacteria that adheres to human gastric mucosa, has been identified to increase GC risk for decades [23]. TLR5 recognizes flagellin, which is the protein monomer that makes up the filament of bacterial flagella, and found on most motile bacteria [24]. Then, Smith et al [25] identified TLR5 was required for Helicobacter pylori-induced NF-kappa B activation and chemokine expression by epithelial cells, and demonstrated that gastric epithelial cells recognized and responded to $\mathrm{H}$. pylori infection via TLR5, which indicated the close relationship between TLR5 and Helicobacter pylori infection. TLR5 is located at 1q41, containing 6 exons. Abnormal TLR5 functioning is related to the onset of gastric, cervical, endometrial and ovarian cancers [26, 27]. In Trejo-de's paper [28], they found that Patients with polymorphisms of TLR5 expressed significantly lower levels of IL-1b, TNF-a, IL-6 and IL10 in gastric tissue. Here, we found TLR5 rs5744174, rs1640827 and rs17163737 were significantly associated with increased GC risk. One previous study found TLR5 rs5744174, and interaction between rs5744174 and $\mathrm{H}$. pylori infection were associated with the development of GC with a smaller sample size [13]. However, we didn't replicate the infection in current study, although we found the significant association between TLR5 rs5744174 and 
Table 1: Distributions of select variables in GC patients and cancer-free controls

\begin{tabular}{|c|c|c|c|}
\hline Characteristics & Cases & Controls & $P$ values \\
\hline Number & 1300 & 1300 & \\
\hline Age $($ mean $\pm \mathrm{SD})$ & $59.99 \pm 10.56$ & $59.35 \pm 9.76$ & 0.109 \\
\hline \multicolumn{4}{|l|}{ Gender } \\
\hline Male & $918(70.6 \%)$ & $933(71.8 \%)$ & 0.496 \\
\hline Female & $382(29.4 \%)$ & $367(28.2 \%)$ & \\
\hline \multicolumn{4}{|l|}{ Education level } \\
\hline$\geq$ Middle school & $270(20.8 \%)$ & $295(22.7 \%)$ & 0.235 \\
\hline$<$ Middle school & $1030(79.2 \%)$ & $1005(77.3 \%)$ & \\
\hline \multicolumn{4}{|l|}{ Residence, $(n(\%))$} \\
\hline Rural & $690(53.1 \%)$ & $634(48.8 \%)$ & 0.028 \\
\hline Urban & $610(46.9 \%)$ & $666(51.2 \%)$ & \\
\hline Body mass index & $22.2 \pm 3.1$ & $22.4 \pm 3.5$ & 0.123 \\
\hline \multicolumn{4}{|l|}{ Smoking status } \\
\hline Yes & $400(30.8 \%)$ & $265(20.4 \%)$ & $<0.001$ \\
\hline No & $900(69.2 \%)$ & $1035(79.6 \%)$ & \\
\hline \multicolumn{4}{|l|}{ Drinking status } \\
\hline Yes & $367(28.2 \%)$ & $325(25.0 \%)$ & 0.062 \\
\hline No & $933(71.8 \%)$ & $975(75.0 \%)$ & \\
\hline \multicolumn{4}{|c|}{ Helicobacter pylori infection } \\
\hline Yes & $800(61.5 \%)$ & $586(45.1 \%)$ & $<0.001$ \\
\hline No & $500(38.5 \%)$ & $714(54.9 \%)$ & \\
\hline
\end{tabular}

Table 2: TagSNP selection of TLR5 gene

\begin{tabular}{|l|c|c|r|l|}
\hline \multicolumn{1}{l}{ TagSNP } & Size & ave.MAF & ave.r2 & SNPs.captured \\
\hline rs5744174 & 8 & 0.1969 & 0.911 & $\begin{array}{l}<\mathrm{CHB}>\text { rs1100886,rs5744174,rs851139,rs851178,rs851180,rs851186,rs8511 } \\
92, \text { rs851193 }\end{array}$ \\
\hline rs5744140 & 6 & 0.083 & 1 & $<\mathrm{CHB}>$ rs5744135,rs5744138,rs5744139,rs5744140,rs5744143,rs5744149 \\
\hline rs5744113 & 5 & 0.2548 & 0.9538 & $<\mathrm{CHB}>$ rs1341987,rs2096141,rs2096142,rs2353476,rs5744113 \\
\hline rs1640827 & 2 & 0.161 & 1 & $<\mathrm{CHB}>$ rs1640827,rs851191 \\
\hline rs2241096 & 1 & 0.311 & 1 & $<\mathrm{CHB}>$ rs2241096 \\
\hline rs17163737 & 1 & 0.286 & 1 & $<\mathrm{CHB}>$ rs17163737 \\
\hline rs2241097 & 1 & 0.137 & 1 & $<\mathrm{CHB}>$ rs2241097 \\
\hline
\end{tabular}

GC risk. Recently, TLR5 rs5744174 was also identified to be significantly associated with HDL-C (recessive model: $\beta=-0.14,95 \% \mathrm{CI}:-0.24$ to $-0.03, P=0.009$ ) [29]. Significant differences were observed in the distribution of alleles and genotypes between the patients with rheumatic heart disease (RHD) and the controls for rs1640827 [30].

Strengths of this study included the large sample size which could provide enough statistical power (the power for rs5744174, rs1640827 and rs17163737 were $88.1 \%, 78.6 \%$, and $82.6 \%$, respectively), the high participation rate, and the homogeneous ethnic background of the participants. Also, some limitations should also be acknowledged in the present study. First, the study population was limited to the Chinese population; second, selection bias may emerge during the recruitment of study percipients, due to the hospital-based study design. Further, results derived from other populations, and association studies between the TLR5 polymorphisms and expression of inflammatory cytokines in the gastric cancer tissues are needed to better understand the complicated mechanisms underlying the modifying effect of the TLR5 gene.

In summary, we identified significant interactions between TLR5 rs1640827, rs17163737 and Helicobacter pylori infection. This results provide valuable insights 
Table 3: Association between TLR5 gene polymorphisms and risk of GC

\begin{tabular}{|c|c|c|c|c|}
\hline Genotype & Cases & Controls & OR $(95 \% \text { CI })^{*}$ & $P$ value \\
\hline \multicolumn{5}{|l|}{$\overline{r s 5744174}$} \\
\hline TT & 794 & 858 & 1.00 (reference) & \\
\hline $\mathrm{TC}$ & 425 & 390 & $1.18(1.00-1.39)$ & 0.047 \\
\hline $\mathrm{CC}$ & 81 & 52 & $1.68(1.18-2.41)$ & 0.004 \\
\hline $\mathrm{T}$ & & & 1.00 (reference) & \\
\hline $\mathrm{C}$ & & & $1.24(1.09-1.42)$ & 0.001 \\
\hline \multicolumn{5}{|l|}{ rs5744140 } \\
\hline $\mathrm{CC}$ & 1069 & 1098 & 1.00 (reference) & \\
\hline $\mathrm{CT}$ & 212 & 189 & $1.15(0.93-1.43)$ & 0.193 \\
\hline $\mathrm{TT}$ & 19 & 13 & $1.50(0.74-3.04)$ & 0.259 \\
\hline $\mathrm{C}$ & & & 1.00 (reference) & \\
\hline $\mathrm{T}$ & & & $1.18(0.97-1.43)$ & 0.089 \\
\hline \multicolumn{5}{|l|}{ rs5744113 } \\
\hline AA & 768 & 772 & 1.00 (reference) & \\
\hline $\mathrm{AG}$ & 440 & 448 & $0.99(0.84-1.16)$ & 0.879 \\
\hline GG & 92 & 80 & $1.15(0.84-1.58)$ & 0.368 \\
\hline A & & & 1.00 (reference) & \\
\hline G & & & $1.03(0.91-1.17)$ & 0.602 \\
\hline \multicolumn{5}{|l|}{ rs1640827 } \\
\hline TT & 842 & 901 & 1.00 (reference) & \\
\hline $\mathrm{TC}$ & 406 & 366 & $1.19(1.00-1.41)$ & 0.048 \\
\hline $\mathrm{CC}$ & 52 & 33 & $1.69(1.08-2.62)$ & 0.021 \\
\hline $\mathrm{T}$ & & & 1.00 (reference) & \\
\hline $\mathrm{C}$ & & & $1.22(1.06-1.41)$ & 0.005 \\
\hline \multicolumn{5}{|l|}{ rs2241096 } \\
\hline GG & 762 & 772 & 1.00 (reference) & \\
\hline $\mathrm{AG}$ & 471 & 456 & $1.05(0.89-1.23)$ & 0.585 \\
\hline AA & 67 & 52 & $1.31(0.89-1.90)$ & 0.164 \\
\hline G & & & 1.00 (reference) & \\
\hline A & & & $1.08(0.95-1.23)$ & 0.231 \\
\hline \multicolumn{5}{|l|}{ rs17163737 } \\
\hline GG & 679 & 745 & 1.00 (reference) & \\
\hline GT & 509 & 468 & $1.19(1.01-1.40)$ & 0.034 \\
\hline $\mathrm{TT}$ & 112 & 87 & $1.41(1.05-1.90)$ & 0.023 \\
\hline G & & & 1.00 (reference) & \\
\hline $\mathrm{T}$ & & & $1.20(1.06-1.35)$ & 0.004 \\
\hline \multicolumn{5}{|l|}{ rs2241097 } \\
\hline AA & 974 & 990 & 1.00 (reference) & \\
\hline $\mathrm{AC}$ & 307 & 296 & $1.05(0.88-1.26)$ & 0.571 \\
\hline $\mathrm{CC}$ & 19 & 14 & $1.38(0.69-2.76)$ & 0.363 \\
\hline A & & & 1.00 (reference) & \\
\hline $\mathrm{C}$ & & & $1.07(0.91-1.26)$ & 0.384 \\
\hline
\end{tabular}

*Adjusted for residence, smoking status and Helicobacter pylori infection 
Table 4: Interaction analyses between TLR5 gene polymorphisms and Helicobacter pylori infection

\begin{tabular}{|c|c|c|c|c|c|c|}
\hline & \multicolumn{6}{|c|}{ Helicobacter pylori infection } \\
\hline & \multicolumn{3}{|c|}{ No } & \multicolumn{3}{|c|}{ Yes } \\
\hline & Case & Control & OR(95\% CI $) *$ & Case & Control & OR(95\% CI $)^{*}$ \\
\hline \multicolumn{7}{|l|}{ rs5744174 } \\
\hline TT & 285 & 467 & 1.00 (reference) & 509 & 391 & $2.13(1.75-2.60)$ \\
\hline \multirow[t]{2}{*}{$\mathrm{TC}+\mathrm{CC}$} & 215 & 247 & $1.43(1.13-1.80)$ & 291 & 195 & $2.23(1.87-2.68)$ \\
\hline & \multicolumn{6}{|c|}{$P$ for interaction $=\mathbf{0 . 1 1 4}$} \\
\hline \multicolumn{7}{|l|}{ rs 1640827} \\
\hline TT & 330 & 515 & 1.00 (reference) & 512 & 386 & $2.07(1.71-2.50)$ \\
\hline \multirow[t]{2}{*}{$\mathrm{TC}+\mathrm{CC}$} & 170 & 199 & $1.33(1.04-1.71)$ & 288 & 200 & $2.13(1.79-2.53)$ \\
\hline & \multicolumn{6}{|c|}{$P$ for interaction $=0.009$} \\
\hline \multicolumn{7}{|l|}{ rs 17163737} \\
\hline GG & 270 & 430 & 1.00 (reference) & 409 & 315 & $2.07(1.67-2.55)$ \\
\hline \multirow[t]{2}{*}{$\mathrm{GT}+\mathrm{TT}$} & 230 & 284 & $1.29(1.02-1.62)$ & 391 & 271 & $2.17(1.81-2.61)$ \\
\hline & \multicolumn{6}{|c|}{$P$ for interaction $=0.006$} \\
\hline
\end{tabular}

*Adjusted for residence, and smoking status

into the TLR5 and Helicobacter pylori infection involved in gastric carcinogenesis, and this may have important implications in personalized prevention of GC.

\section{MATERIALS AND METHODS}

\section{Study subjects}

In current study, all cases were confirmed by examination of gastroscopy biopsy or surgical specimens, while the age, gender, and education level matched controls were randomly enrolled during the same time period, and were confirmed to have no current or previous signs of cancer. Information on age, gender, education levels, residence, smoking status, drinking status, and body mass index were obtained by questionnaires. A 5-mL blood sample was collected from each subject. All subjects gave written informed consent for this study, and this study was approved by the appropriate Ethics Committee.

\section{DNA extraction and genotyping}

Genomic DNA was isolated from peripheral blood using the QIAamp DNA Blood Maxi Kit (Qiagen, Hilden, Germany) according to the manufacturer's protocol. TagSNPs of TLR5 based on SNPs with minor allele frequencies (MAF) greater than 0.05 in CHB (Han Chinese in Beijing, China) population were selected using the web-based software SNPinfo (http://snpinfo.niehs.nih. gov/), which produced 7 tagSNPs (Table 2). Genotyping were conducted using Sequenom MassARRAY platform, while Sequenom Typer 4.0 software (Sequenom) was used for data management and analyses. Randomly selected 5\% of samples were run in duplicates and the concordance of genotype calls was $100 \%$ for duplicate samples. All laboratory personnel were blinded to the case-control status of the study subjects.

\section{Determination of Helicobacter pylori infection}

Sero-status of antibodies to four H. pylori specific antigens (CagA, VacA, UreA and UreB) was determined using Typing Detection Kit for Antibody to H. pylori (Shenzhen Blot Biotech Co., Ltd, Shenzhen, China) according to the manufacturer's instructions. $\mathrm{H}$. pylori sero-positivity was defined as any of the CagA, VacA, UreA or UreB being seropositive.

\section{Statistical analysis}

All the statistical analysis was performed by SPSS 19.0 software (IBM Corporation, Armonk, NY, USA). All statistical tests were two-tailed, and a $P$-value $<0.05$ was considered statistically significant. Hardy-Weinberg equilibrium (HWE) was assessed by Pearson's goodness-of-fit Chi-square $(\chi 2)$ statistic for each SNP. The differences of qualitative characteristics were analyzed using the $\chi 2$ test, while continuous variables were expressed as the mean \pm standard deviation (SD), and were tested by the student's $t$ test. Odds ratios (ORs) with 95\% confidence intervals (CIs) were calculated for each allele in both the patient and control groups, using a binary logistic regressive analysis by adjusting for potential confounding factors. A likelihood ratio test was conducted by comparing the model including only the main effects with that including both the main effects and the interaction terms to derive the $P$ value for the multiplicative interaction test. 


\section{ACKNOWLEDGMENTS AND FUNDING}

This study was supported by Quanzhou science and technology project (2014Z27), and the scientific research project of Second Affiliated Hospital of Fujian Medical University (2013MP09).

\section{CONFLICTS OF INTEREST}

The authors declare that they have no conflicts of interest.

\section{REFERENCES}

1. Fan QH, Yu R, Huang WX, Cui XX, Luo BH, Zhang LY. The has-miR-526b binding-site $\mathrm{rs} 8506 \mathrm{G}>\mathrm{a}$ polymorphism in the lincRNA-NR_024015 exon identified by GWASs predispose to non-cardia gastric cancer risk. PLoS One. 2014; 9:e90008.

2. Torre LA, Bray F, Siegel RL, Ferlay J, Lortet-Tieulent J, Jemal A. Global cancer statistics, 2012. CA Cancer J Clin. 2015; 65:87-108.

3. Siegel RL, Miller KD, Jemal A. Cancer statistics, 2016. CA Cancer J Clin. 2016; 66:7-30.

4. Chen W, Zheng R, Baade PD, Zhang S, Zeng H, Bray F, Jemal A, Yu XQ, He J. Cancer statistics in China, 2015. CA Cancer J Clin. 2016.

5. Zhou X, Chen H, Zhu L, Hao B, Zhang W, Hua J, Gu H, Jin $\mathrm{W}$, Zhang G. Helicobacter pylori infection related long noncoding RNA (lncRNA) AF147447 inhibits gastric cancer proliferation and invasion by targeting MUC2 and up-regulating miR-34c. Oncotarget. 2016; 7:82770-82782. doi: 10.18632/oncotarget.13165.

6. Bessede E, Molina S, Acuna Amador L, Dubus P, Staedel C, Chambonnier L, Buissonniere A, Sifre E, Giese A, Benejat L, Rousseau B, Costet P, Sacks DB, et al. Deletion of IQGAP1 promotes Helicobacter pylori-induced gastric dysplasia in mice and acquisition of cancer stem cell properties in vitro. Oncotarget. 2016; 7:80688-80699. doi: 10.18632/oncotarget.12486.

7. Roy RK, Hoppe MM, Srivastava S, Samanta A, Sharma N, Tan KT, Yang H, Voon DC, Pang B, Teh M, MurataKamiya N, Hatakeyama M, Chang YT, et al. CEACAM6 is upregulated by Helicobacter pylori CagA and is a biomarker for early gastric cancer. Oncotarget. 2016; 7:55290-55301. doi: 10.18632/oncotarget.10528.

8. Perez-Rodriguez M, Partida-Rodriguez O, CamorlingaPonce M, Flores-Luna L, Lazcano E, Gomez A, HerreraGoepfert R, Medrano-Guzman R, Torres J. Polymorphisms in HLA-DQ genes, together with age, sex, and Helicobacter pylori infection, as potential biomarkers for the early diagnosis of gastric cancer. Helicobacter. 2016.

9. Chen XZ, Schottker B, Castro FA, Chen H, Zhang Y, Holleczek B, Brenner H. Association of helicobacter pylori infection and chronic atrophic gastritis with risk of colonic, pancreatic and gastric cancer: A ten-year follow-up of the ESTHER cohort study. Oncotarget. 2016; 7:17182-17193. doi: 10.18632/oncotarget.7946.

10. Amieva M, Peek RM, Jr. Pathobiology of Helicobacter pyloriInduced Gastric Cancer. Gastroenterology. 2016; 150:64-78.

11. Jeong M, Park JM, Han YM, Park KY, Lee DH, Yoo JH, Cho JY, Hahm KB. Dietary prevention of Helicobacter pylori-associated gastric cancer with kimchi. Oncotarget. 2015; 6:29513-29526. doi: 10.18632/oncotarget.4897.

12. Qadri Q, Rasool R, Afroze D, Naqash S, Gulzar GM, Yousuf A, Siddiqi MA, Shah ZA. Study of TLR4 and IL-8 gene polymorphisms in H.pylori-induced inflammation in gastric cancer in an ethnic Kashmiri population. Immunological investigations. 2014; 43:324-336.

13. Zeng HM, Pan KF, Zhang Y, Zhang L, Ma JL, Zhou T, Su HJ, Li WQ, Li JY, Gerhard M, Classen M, You WC. Genetic variants of toll-like receptor 2 and 5, helicobacter pylori infection, and risk of gastric cancer and its precursors in a chinese population. Cancer Epidemiol Biomarkers Prev. 2011; 20:2594-2602.

14. Castano-Rodriguez N, Kaakoush NO, Pardo AL, Goh KL, Fock KM, Mitchell HM. Genetic polymorphisms in the Toll-like receptor signalling pathway in Helicobacter pylori infection and related gastric cancer. Hum Immunol. 2014; 75:808-815.

15. Wu MS, Cheng TY, Shun CT, Lin MT, Chen LC, Lin JT. Functional polymorphisms of $\mathrm{CD} 14$ and toll-like receptor 4 in Taiwanese Chinese with Helicobacter pylori-related gastric malignancies. Hepatogastroenterology. 2006; 53:807-810.

16. Ding SZ, Torok AM, Smith MF Jr, Goldberg JB. Toll-like receptor 2-mediated gene expression in epithelial cells during Helicobacter pylori infection. Helicobacter. 2005; 10:193-204.

17. Pfirschke C, Garris C, Pittet MJ. Common TLR5 mutations control cancer progression. Cancer Cell. 2015; 27:1-3.

18. Rutkowski MR, Stephen TL, Svoronos N, Allegrezza MJ, Tesone AJ, Perales-Puchalt A, Brencicova E, EscovarFadul X, Nguyen JM, Cadungog MG, Zhang R, Salatino M, Tchou J, et al. Microbially driven TLR5-dependent signaling governs distal malignant progression through tumorpromoting inflammation. Cancer Cell. 2015; 27:27-40.

19. Klimosch SN, Forsti A, Eckert J, Knezevic J, Bevier M, von Schonfels W, Heits N, Walter J, Hinz S, Lascorz J, Hampe J, Hartl D, Frick JS, et al. Functional TLR5 genetic variants affect human colorectal cancer survival. Cancer Res. 2013; 73:7232-7242.

20. Grimm M, Munz A, Exarchou A, Polligkeit J, Reinert S. Immunohistochemical detection of Helicobacter pylori without association of TLR5 expression in oral squamous cell carcinoma. Journal of oral pathology \& medicine. 2014; 43:35-44.

21. Schmausser B, Andrulis M, Endrich S, Lee SK, Josenhans C, Muller-Hermelink HK, Eck M. Expression 
and subcellular distribution of toll-like receptors TLR4, TLR5 and TLR9 on the gastric epithelium in Helicobacter pylori infection. Clinical and experimental immunology. 2004; 136:521-526.

22. Lee SK, Stack A, Katzowitsch E, Aizawa SI, Suerbaum S, Josenhans C. Helicobacter pylori flagellins have very low intrinsic activity to stimulate human gastric epithelial cells via TLR5. Microbes and infection. 2003; 5:1345-1356.

23. Parsonnet J, Friedman GD, Vandersteen DP, Chang Y, Vogelman JH, Orentreich N, Sibley RK. Helicobacter pylori infection and the risk of gastric carcinoma. N Engl J Med. 1991; 325:1127-1131.

24. Hayashi F, Smith KD, Ozinsky A, Hawn TR, Yi EC, Goodlett DR, Eng JK, Akira S, Underhill DM, Aderem A. The innate immune response to bacterial flagellin is mediated by Toll-like receptor 5. Nature. 2001; 410:1099-1103.

25. Smith MF, Jr., Mitchell A, Li G, Ding S, Fitzmaurice AM, Ryan K, Crowe S, Goldberg JB. Toll-like receptor (TLR) 2 and TLR5, but not TLR4, are required for Helicobacter pylori-induced NF-kappa B activation and chemokine expression by epithelial cells. J Biol Chem. 2003; 278:32552-32560.
26. Castano-Rodriguez N, Kaakoush NO, Mitchell HM. Pattern-recognition receptors and gastric cancer. Frontiers in immunology. 2014; 5:336.

27. Husseinzadeh N, Davenport SM. Role of toll-like receptors in cervical, endometrial and ovarian cancers: a review. Gynecol Oncol. 2014; 135:359-363.

28. Trejo-de la OA, Torres J, Sanchez-Zauco N, PerezRodriguez M, Camorlinga-Ponce M, Flores-Luna L, Lazcano-Ponce E, Maldonado-Bernal C. Polymorphisms in TLR9 but not in TLR5 increase the risk for duodenal ulcer and alter cytokine expression in the gastric mucosa. Innate immunity. 2015; 21:706-713.

29. Gu L, Huang J, Tan J, Wei Q, Jiang H, Shen T, Liang B, Tang N. Impact of TLR5 rs5744174 on stroke risk, gene expression and on inflammatory cytokines, and lipid levels in stroke patients. Neurological sciences. 2016; 37:1537-1544.

30. Zhu L, Zou LJ, Hua R, Li B. Association of singlenucleotide polymorphisms in toll-like receptor 5 gene with rheumatic heart disease in Chinese Han population. Int $\mathbf{J}$ Cardiol. 2010; 145:129-130. 